\title{
Influence of weaning timing advice and associated weaning behaviours in a survey of black and minority ethnic groups in the UK
}

\author{
Amanda P Moore, Kristina Nanthagopan, Grace Hammond, Peter Milligan and \\ Louise M Goff* \\ Diabetes and Nutritional Sciences Division, School of Medicine, King's College London, Franklin-Wilkins \\ Building, Room 4.10, Stamford Street, London SEl 9NH, UK
}

Submitted 18 February 2013: Final revision received 4 June 2013: Accepted 25 July 2013: First published online 13 September 2013

\begin{abstract}
Objective: To assess understanding of the Department of Health weaning guidelines and weaning influences in a self-selected sample of black and minority ethnic (BME) parents, residing in London.

Design: A face-to-face, questionnaire-facilitated survey among Black African, Black Caribbean and South Asian parents.

Setting: An opportunistic sample of parents was recruited from Sure Start centres, churches and play groups across key London boroughs.

Subjects: Three hundred and forty-nine interviews were included; 107 Black African, fifty-four Black Caribbean, 120 South Asian and sixty-four of Black mixed-race ethnicity.

Results: Fifty-two per cent of Black and $66 \%$ of South Asian parents had accurate understanding of the guidelines. Inaccurate knowledge of the guidelines was associated with weaning before 17 weeks $(P<0 \cdot 001)$; 36\% of Black Africans and $31 \%$ of Black Caribbeans were weaned before 4 months compared with $16 \%$ of South Asians. All BME groups were most influenced by weaning information from the previous generations of mothers in their families, which was associated with earlier weaning $(21.5$ (SD 6.5) v. 24.1 (SD 4.2) weeks; $F(2,328)=5 \cdot 79$, $P=0 \cdot 003$ ), and less so by professional infant feeding advice, which was associated with a later weaning age (23.7 (SD 5.1) v. 20.7 (SD 5.7) weeks; $F(1,344)=34 \cdot 7, P<0 \cdot 001)$.

Conclusions: Lack of awareness of the Department of Health weaning guidelines is common among these BME populations, whose weaning behaviour is strongly influenced by informal advice. Further research is necessary to elucidate the influences on weaning in these populations and to facilitate the development of infant feeding support which is salient for BME groups in the UK.
\end{abstract}

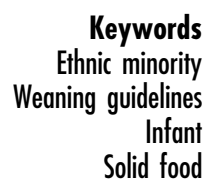

Inappropriate weaning, early and late, is associated with detrimental health outcomes for the infant such as increased risk of diabetes and obesity, as well as respiratory and autoimmune illnesses, nutrient deficiencies and feeding problems $^{(1-4)}$. Weaning refers to the introduction of food other than breast milk or breast-milk substitutes and guidelines from the UK Department of Health (DH) promote weaning around 6 months ${ }^{(5)}$. However, evidence suggests that only a small percentage of mothers wait this long ${ }^{(6)}$, even though knowledge of the guidelines among parents is good and promotes later weaning ${ }^{(7)}$. Early weaning practices are associated with poor awareness of weaning guidelines, which is particularly apparent in young mothers, those receiving benefits and those with low educational attainment ${ }^{(7)}$.
Black and minority ethnic (BME) groups in the UK are recognised to lack engagement with health care ${ }^{(8)}$ and mothers from these groups are one of the priorities for infant feeding education ${ }^{(9,10)}$. There has been limited work undertaken with mothers from BME groups in the UK to understand their weaning behaviours. Ethnicity data from the most recent UK DH Infant Feeding Survey (2010) suggest that mothers from BME groups share many of the same influences on weaning timing as Caucasian mothers; while $30 \%$ of Caucasian mothers have weaned before 17 weeks, $33 \%$ of Black mothers and just 24\% South Asian mothers have done so. However, the BME groups show a tendency to wean very early, which is less apparent in Caucasians ${ }^{(11)}$. Other work suggests inappropriately late weaning may be an issue in 
South Asian communities ${ }^{(12)}$. Distinct cultural differences in the type of foods first introduced, some weaning beliefs and the strong role of family influencers ${ }^{(13,14)}$ have been suggested and qualitative research from DH has indicated that health visitors feel they lack adequate resources to deal with weaning issues in BME populations ${ }^{(13)}$.

The aim of the current investigation was to assess awareness of the weaning guidelines in UK BME groups and understand how this knowledge and other factors influence weaning behaviour. This is important if the $\mathrm{DH}$ wishes to develop cultural competency in staff providing infant feeding education to BME sectors of the UK population and to influence cultural infant feeding practices.

\section{Experimental methods}

\section{Study design}

A survey of parents of South Asian, Black Caribbean and Black African ethnicity was performed using face-to-face interviews. The questionnaire was approved, and the interviews conducted, in accordance with the ethical standards of King's College London Research Ethics Committee (BDM/09/10-61). The survey, originally used for online data collection, has been previously reported ${ }^{(7,15)}$. Data collection took place from June 2010 to April 2011.

\section{Recruitment of sample}

An opportunistic sample of parents was recruited from London boroughs that have a high percentage BME population (Barnet, Brent, Harrow, Southwark, Croydon, Lewisham, Lambeth and Merton, for example); in addition, community groups such as the Tamil Welfare Centre and the London Ghana Seventh-Day Adventist Church were selected to improve access to our target populations. The interviewer guided participants through the questionnaire, taking approximately $10 \mathrm{~min}$. The interviewers were from the represented ethnicities. The interviews were conducted in English and we were not aware of any language barriers but the interviewers were able to facilitate in the local language if necessary. Participation was voluntary and no incentives were offered for participation.

Eligible participants were resident in the UK and had weaned a child since the introduction of the current guidelines (2003). A series of explicit questions was used to assess all inclusion criteria. Data were excluded if the most recently weaned child had been weaned early or late for medical reasons. Ethnicity was self-declared; South Asian ethnicity includes people of Indian, Pakistani, Bangladeshi and Sri Lankan descent.

\section{Survey design}

The questionnaire was piloted in face-to-face interviews and three questions were adapted to facilitate understanding and analysis. No personal, identifiable data were collected. The survey consisted of twenty-one questions (four with sub-sections, giving fifty-three questions in total) in themed sections: weaning timing; understanding of the guidelines; factors influencing weaning timing; sources of information; antenatal care; feeding choices; and feelings about the weaning process. Questions concerning the guidelines allowed respondents to tick one of five options to describe their understanding of the guidelines ('You should start weaning your baby: (1) at 6 months; (2) between the ages of 4 and 6 months; (3) when they show signs of being ready to eat solids (e.g. holding their head up, reaching for food); (4) after 17 weeks; (5) around 6 months when your baby shows signs of being ready and solids should not be introduced before 17 weeks'. Both the first and last options were deemed as 'accurate'. Alternatively, respondents could indicate their own different understanding or if they were unaware of the guidelines). Weaning was defined for participants as the introduction of any food other than breast milk or breast-milk substitute (formula milk). Factors influencing the decision to begin weaning were measured on a 4-point scale (from 'a lot of influence' to 'no influence', excluding the neutral position). A collection of eight questions about feelings surrounding the weaning experience were measured on a 5-point scale (from 'strongly agree' to 'strongly disagree' and including a neutral position). Parents answered the questions in relation to their most recently weaned child.

\section{Statistical analysis}

Analysis was carried out using the statistical software package IBM SPSS Statistics $19 \cdot 0$. All questionnaires that gave demographic data, ethnicity and weaning timing information were included in the analysis. Questions were optional; however, the majority of questionnaires were completed fully, only eighteen held any missing information; no questionnaires that were less than $97 \%$ complete were included in the analysis. Missing data analyses were carried out as a standard procedure. In all instances $P>0.05$ (data not shown), leading us to conclude that missing data is not significantly influencing our results. Valid percentages are shown. Black African, Black Caribbean, South Asian and Black mixed-race, where possible, were analysed and reported separately; when they were analysed collectively, it is specified in the text. It was not possible to analyse Black African mixed-race and Black Caribbean mixed-race separately as these groups were small. Non-parametric tests were used to assess the relationship between categorical variables and one-way ANOVA modelling was performed using the ranked weaning weeks, due to the ordinal nature of the data. To assess factors associated with weaning timing the following factors were included in the model: receipt of benefits, marital status, maternal age, educational attainment, understanding of the guidelines, most influential source of advice, attendance at antenatal care, exclusive breast-feeding to 8 weeks and ethnicity. 
Questions concerning factors influencing the decision to wean were treated as separate Likert items and analysed using non-parametric tests as previously recommended ${ }^{(16,17)}$. A collection of eight questions concerning attitude to weaning were measured on a traditional 5-point Likert scale and analysed collectively using ANOVA analysis of means, to give a general attitudinal score to the weaning experience $^{(16,17)}$. Following ANOVA analyses Tukey post hoc tests were carried out where appropriate to understand the variance between groups.

\section{Results}

A total of 349 interviews were included in the analysis (Table 1). Ninety-three per cent of respondents were the mother, $6 \%$ the father and $1 \%$ were other carers; the mean respondent age was $31(\mathrm{SD} 6.0$ ) years. Overall the sample was well-educated with $61 \%$ having a degree/ professional qualification. There was no difference in level of education between ethnicities; however, the Black mixed-race groups were more likely to be on benefits than any of the other groups $\left(\chi^{2}(3,338)=77 \cdot 63\right.$, $P<0 \cdot 001)$. Single parenthood was less common among South Asian than Black respondents $\left(\chi^{2}(3,341)=53 \cdot 20\right.$, $P<0 \cdot 001$ ). At the time of participation $27 \%$ of respondents indicated that their most recently weaned child was under 1 year old; for $57 \%$ their most recently weaned child was between 1 and 3 years old and for $16 \%$ the youngest child was $4-7$ years old. Fifty per cent were firsttime mothers, $30 \%$ had two children and $20 \%$ three or more children. Seventy-two per cent of the sample exclusively breast-fed their most recently weaned child for a minimum of 8 weeks and there was no difference in this between ethnicities.

Fifty-six per cent of respondents had accurate knowledge of the guidelines, with $33 \%$ reporting their understanding to be to wean 'at 6 months' and $23 \%$ 'around 6 months'; both these responses were deemed accurate. Accurate knowledge was associated with a later weaning age (23.7 (SD 5.1) v. 20.7 (SD 5.7) weeks in those who did not have accurate knowledge; $F(1,344)=34 \cdot 7$, $P<0 \cdot 001)$. Those reporting accurate knowledge of the guidelines were less likely to wean before 17 weeks $\left(\chi^{2}(9,330)=58 \cdot 82, P<0 \cdot 001\right)$ compared with those who did not. There was an association between knowledge of the guidelines and maternal age, with those under 25 years old being less likely to have accurate knowledge $\left(\chi^{2}(2,351)=8 \cdot 27, P=0 \cdot 016\right)$. There was no association between knowledge of the guidelines and socio-economic or educational status. The majority of participants had received advice from their health visitor about when to wean (75\%) and those receiving advice from health visitors were more likely to report they were given clear advice about the guidelines $(F(1,366)=52 \cdot 21, P<0 \cdot 001)$.

\section{Weaning behaviour in Black Caribbean and Black African communities}

Weaning age and understanding of the guidelines

Black ethnicities had a significantly earlier weaning age than South Asian respondents $(F(3,329)=4 \cdot 77, P=0 \cdot 003)$, with $31 \%$ of Black Africans and $36 \%$ of Black Caribbeans weaning before 17 weeks (Table 1). Furthermore, very early introduction of solids ( $0-8$ weeks) was indicated by $4 \%$ of the Black respondents. Among the Black ethnicities there was greater spread in the age of introducing solids compared with the South Asian group and it was earliest among the Black Africans. The Black mixed-race ethnicities were less likely to wean before 17 weeks than the other Black respondents $\left(\chi^{2}(9,330)=57 \cdot 66, P<0 \cdot 001\right)$.

Fifty-two per cent of the Black participants had accurate knowledge of the weaning guidelines and the Black ethnicities, collectively and individually, were less likely to have an accurate understanding than the South Asian group (Fig. 1).

\section{Engagement with medical advice}

Self-reported attendance at antenatal classes among Black Caribbean first-time mothers was the lowest of the ethnicities at $42 \%$ (Black African 66\%, South Asian 78\%, Black mixed-race $\left.68 \% ; \quad \chi^{2}(3,171)=10 \cdot 00, \quad P=0 \cdot 019\right)$. Among Black ethnicities, $75 \%$ of the respondents reported receiving weaning advice from a health visitor and the baby was a mean age of 6.4 (SD 8.6 ) weeks when advice was received. Health visitor advice was the most important source of advice for $31 \%$ of Black respondents. The Black Caribbean population was most likely to report that health visitor advice was of 'no influence' compared with the other ethnic groups surveyed ('no influence': Black Caribbeans 36\%, Black Africans 21\%, South Asians 24\% and Black mixed-race $6 \% ; \chi^{2}(9,330)=25 \cdot 03, P=0 \cdot 001$; Table 2). However, when health visitor advice was received it resulted in a later weaning age across all the Black ethnic groups reported $(F(1,323)=12 \cdot 00, P=0 \cdot 001)$.

\section{Other weaning information sources}

For Black Caribbean, Black African and Black mixed-race ethnicities, the most influential source of weaning advice was that from the previous generation of mothers and grandmothers within the family; $41 \%, 33 \%$ and $49 \%$ of these mothers, respectively, indicated this advice was most influential. Being most influenced by this informal, rather than formal health-care advice (advice from a health visitor, general practitioner or other medical practitioner such as a dietitian) was independently associated with earlier weaning in all ethnicities (informal advice 21.5 (SD 6.5) weeks $v$. formal advice $24 \cdot 1$ (SD $4 \cdot 2$ ) weeks; $F(2,328)=5 \cdot 79, \quad P=0 \cdot 003)$. Experience from previous children was an important influence for parents with more than one child, although they still stated the mother/grandmother as the most influential information 
Table 1 Characteristics according to ethnicity among a self-selected sample of black and minority ethnic parents residing in London, UK, June 2010-April 2011

\begin{tabular}{|c|c|c|c|c|c|c|c|c|c|c|c|c|c|}
\hline & \multicolumn{2}{|c|}{$\begin{array}{l}\text { Black Caribbean } \\
\qquad(n 54)\end{array}$} & \multicolumn{2}{|c|}{$\begin{array}{l}\text { Black African } \\
\quad(n \text { 107) }\end{array}$} & \multicolumn{2}{|c|}{$\begin{array}{l}\text { South Asian } \\
\quad(n 120)\end{array}$} & \multicolumn{2}{|c|}{$\begin{array}{l}\text { White \& Black Caribbean } \\
\qquad(n 9)\end{array}$} & \multicolumn{2}{|c|}{$\begin{array}{l}\text { White \& Black African } \\
\qquad(\text { ( } 59)\end{array}$} & \multicolumn{2}{|c|}{$\begin{array}{l}\text { Total sample } \\
\quad(n \text { 349) }\end{array}$} & \multirow[b]{2}{*}{$P$} \\
\hline & Mean or $n$ & SD or $\%$ & Mean or $n$ & SD or $\%$ & Mean or $n$ & SD or $\%$ & Mean or $n$ & SD or \% & Mean or $n$ & SD or $\%$ & Mean or $n$ & SD or $\%$ & \\
\hline Weaning age (weeks) & $21 \cdot 1$ & $7 \cdot 4$ & $20 \cdot 9^{a}$ & $5 \cdot 9$ & $23 \cdot 0^{\mathrm{b}}$ & $4 \cdot 3$ & $22 \cdot 9$ & $5 \cdot 4$ & $24 \cdot 2^{b}$ & $5 \cdot 1$ & $22 \cdot 5$ & $5 \cdot 6$ & $0.003^{\star}$ \\
\hline Maternal age (years) & $32 \cdot 4$ & $7 \cdot 5$ & $32 \cdot 1$ & $5 \cdot 5$ & $31 \cdot 5$ & $5 \cdot 3$ & $28 \cdot 4$ & $5 \cdot 5$ & $28 \cdot 7$ & $5 \cdot 4$ & $31 \cdot 1$ & $6 \cdot 0$ & $0.463^{*}$ \\
\hline \multicolumn{14}{|c|}{ Age by which solids introduced, $n(\%)$} \\
\hline 8 weeks & 3 & 6 & 4 & 4 & 1 & $<1$ & 1 & $<1$ & 1 & 2 & 10 & 3 & \\
\hline 13 weeks & 5 & 10 & 10 & 9 & 2 & 2 & 1 & $<1$ & 2 & 4 & 17 & 5 & \\
\hline 13 weeks & 17 & 31 & 39 & 36 & 19 & 16 & 2 & 22 & 4 & 6 & 80 & 23 & \\
\hline 22 weeks & 25 & 47 & 58 & 54 & 44 & 37 & 5 & 55 & 14 & 24 & 147 & 42 & \\
\hline 26 weeks & 45 & 84 & 98 & 92 & 104 & 87 & 8 & 88 & 46 & 78 & 300 & 86 & \\
\hline 29 weeks & 54 & 100 & 107 & 100 & 120 & 100 & 9 & 100 & 59 & 100 & 349 & 100 & \\
\hline \multicolumn{14}{|l|}{ Education, $n(\%)$} \\
\hline To age 16 & 6 & 13 & 9 & 10 & 15 & 13 & 3 & 38 & 5 & 9 & 38 & 12 & $0.072 \downarrow$ \\
\hline To age 18 & 18 & 41 & 29 & 31 & 25 & 22 & 2 & 25 & 8 & 13 & 82 & 26 & \\
\hline Degree/equivalent & 21 & 46 & 56 & 59 & 72 & 65 & 3 & 38 & 45 & 78 & 197 & 62 & \\
\hline In receipt of benefits, $n(\%)$ & 19 & 36 & 26 & 26 & 29 & 24 & 5 & 62 & 52 & 88 & 141 & 40 & $<0.001 \ddagger$ \\
\hline \multicolumn{14}{|l|}{ Marital status, $n(\%)$} \\
\hline Single/divorced & 25 & 47 & 23 & 23 & 5 & 4 & 5 & 55 & 1 & 2 & 59 & 17 & 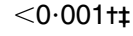 \\
\hline Co-habiting & 5 & 9 & 8 & 8 & 1 & 1 & 1 & 11 & 1 & 2 & 16 & 5 & \\
\hline Married & 23 & 44 & 69 & 69 & 114 & 95 & 3 & 34 & 57 & 96 & 266 & 78 & \\
\hline \multicolumn{14}{|l|}{ Number of children, $n(\%)$} \\
\hline 1 & 26 & 49 & 44 & 41 & 54 & 45 & 7 & 78 & 40 & 68 & 171 & 49 & $<0.007 t \ddagger$ \\
\hline 2 & 14 & 26 & 34 & 32 & 43 & 36 & 2 & 22 & 13 & 22 & 106 & 30 & \\
\hline 3 or more & 13 & 25 & 29 & 27 & 23 & 19 & 0 & 0 & 6 & 10 & 71 & 20 & \\
\hline \multicolumn{14}{|c|}{ Age of most recently weaned child, $n(\%)$} \\
\hline$<1$ years & 11 & 21 & 26 & 25 & 31 & 26 & 2 & 22 & 25 & 42 & 95 & 27 & $0.074 t \ddagger$ \\
\hline $1-3$ years & 33 & 62 & 63 & 59 & 72 & 60 & 7 & 78 & 22 & 37 & 197 & 57 & \\
\hline $4+$ years & 9 & 17 & 17 & 16 & 17 & 14 & 0 & 0 & 12 & 21 & 55 & 16 & \\
\hline
\end{tabular}

${ }^{\text {a.b }}$ Mean values within a row with unlike superscript letters were significantly different $(P=0.05)$. Values in the same row with no superscript letter were not included in the test. ${ }^{*}$ ANOVA analysis of means.

$+\chi^{2}$ analysis comparing between ethnic groups.

$\ddagger$ Analysis used combined mixed-race group as numbers too small to analyse separately. 


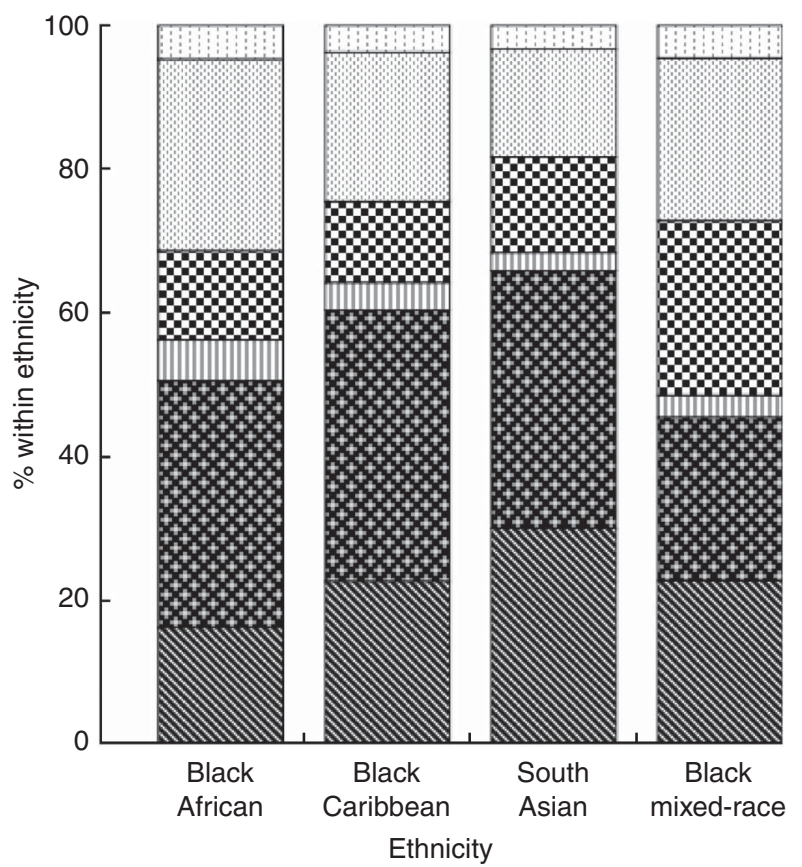

Fig. 1 Understanding of the Department of Health weaning guidelines ( $\square$, I am not aware of the weaning guidelines; $\square$, between the ages of 4 and 6 months; $\%$, when the baby shows signs of being ready; 四, after 17 weeks when the baby shows signs of being ready; at 6 months; around 6 months when the baby shows signs of being ready (not before 17 weeks) ${ }^{\star}$ ) by ethnicity in a self-selected sample of black and minority ethnic parents residing in London, UK, June 2010-April 2011. *'At 6 months' or 'around 6 months' were both deemed as accurate. $\chi^{2}(3,344)=9 \cdot 40, P=0.024$ across ethnicities comparing accurate understanding of the guidelines

source (Table 3). Black Caribbean mothers reported the most common advice given to them by friends and family was to wean when the baby showed signs of readiness (37\%), while for Black African and Black mixed-race mothers it was to wean between 4 and 6 months (37\%).

Factors associated with the decision to begin weaning Black ethnicities were most influenced, in their decision to begin weaning, by the baby showing signs of readiness to accept solids (62\% of Black Africans, $61 \%$ of Black Caribbeans and $44 \%$ of Black mixed-race said this had 'a lot of influence'). While the baby waking at night was an important factor in beginning to wean for $30 \%$ of the Black population sampled, it was of less influence for the Black Caribbean participants than for Black Africans $\left(\chi^{2}(9,323)=32 \cdot 68, P<0 \cdot 001\right)$. Being influenced by the baby waking in the night was associated with an earlier weaning age (mean weaning age $20 \cdot 1$ (SD 5.6) v. $23 \cdot 1$ (SD 5.2) weeks for those who were not influenced by this factor; $F(3,327)=3 \cdot 95, P=0 \cdot 009)$. These respondents were also more likely to wean before 17 weeks $\left(\chi^{2}(2,328)=11 \cdot 48, P=0 \cdot 003\right)$.

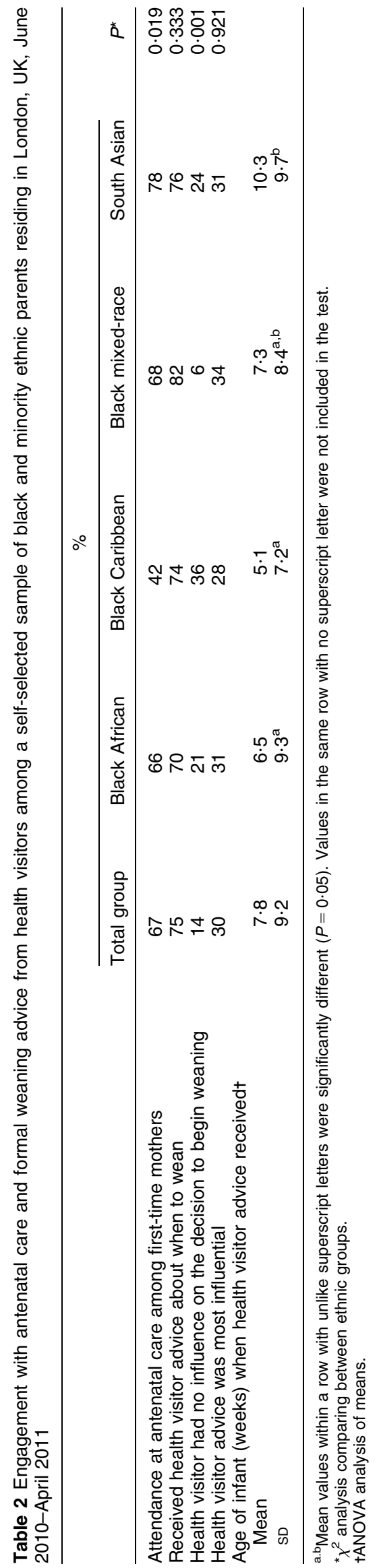


Feelings about weaning

The attitude to the weaning experience was generally favourable among the Black ethnicities although less favourable than for their South Asian counterparts $(P=0.049$; Table 4). In particular the Black ethnicities reported a lower level of agreement with the statement 'I was given clear advice about the current guidelines' compared with the South Asians $(F(3,246)=5 \cdot 85, P<0 \cdot 001$; Table 4).

Within Black respondents, those of Black mixed-race reported a less favourable experience than the other Black groups $(P<0 \cdot 001)$. In particular, the Black mixedrace respondents were less confident about when to wean $(F(3,347)=7 \cdot 5, P<0 \cdot 001)$ and were more anxious $(F(3,343)=6 \cdot 3, P<0 \cdot 001)$ and confused $(F(3,343)=7 \cdot 3$, $P<0 \cdot 001)$ than other Black ethnic groups (Table 4).

\section{Factors associated with weaning timing in Black ethnic groups.}

In the Black population having an accurate knowledge of the $\mathrm{DH}$ guidelines was independently associated with a later weaning age $(F(1,188)=6.31, P=0.003)$ after adjustment for demographic factors, while relying on mothers/grandmothers as the most influential source of weaning advice was independently associated with earlier weaning (mean weaning age $20 \cdot 8$ (sD 6.5) v. 23.4 (sD 4.2) weeks for those relying on formal advice; $F(2,188)=3 \cdot 12$, $P=0 \cdot 046$ ). Accurate knowledge of the $\mathrm{DH}$ guidelines was also independently associated with choosing to exclusively breast-feed for the first 8 weeks $(F(1,188)=7 \cdot 27$, $P=0 \cdot 008)$ and ethnicity $(F(2,188)=3 \cdot 84, P=0 \cdot 003)$.

\section{Weaning behaviour in the Soutb Asian community}

Weaning age and understanding of the guidelines in the South Asian community

The mean weaning age for South Asian respondents was 23.0 (SD 4.3) weeks (Table 1). There was less variability in the weaning age in the South Asian population sampled, with $16 \%$ weaning before 17 weeks and $87 \%$ having weaned by 26 weeks (Table 1 ).

In total, $66 \%$ of the South Asian population reported accurate understanding of the DH guidelines (Fig. 1).

Engagement with medical advice and other sources of weaning information in the South Asian community

South Asian first-time mothers reported $78 \%$ attendance at antenatal classes. Seventy-six per cent of mothers reported receiving weaning advice from a health visitor, which was associated with a later weaning age $(F(1,323)=$ $12 \cdot 00, P=0 \cdot 001)$. The age of the baby when health visitor advice was received was $10 \cdot 3$ (SD 6.6) weeks (later than in the Black population, $P=0 \cdot 004)$. The previous generation (mother/grandmother) was the most influential source of information for $32 \%$ of South Asian mothers. South Asian mothers also reported a higher use of the Internet as a source of weaning advice than other ethnicities (Table 3). 
Table 4 Likert scale data summarising attitude to weaning advice in a self-selected sample of black and minority ethnic parents residing in London, UK, June 2010-April 2011

\begin{tabular}{|c|c|c|c|c|c|c|c|}
\hline \multirow[b]{2}{*}{ Feelings about weaning ( $1=$ strongly agree, $5=$ strongly disagree $)$} & \multirow[b]{2}{*}{$n$} & \multirow[b]{2}{*}{ Mean } & \multicolumn{5}{|c|}{$\%$} \\
\hline & & & $\begin{array}{l}\text { Strongly } \\
\text { agree }\end{array}$ & Agree & Neither & Disagree & $\begin{array}{l}\text { Strongly } \\
\text { disagree }\end{array}$ \\
\hline \multicolumn{8}{|l|}{ I received conflicting advice $\left(P^{\star}=0.693\right)$} \\
\hline Black African & 96 & $3 \cdot 2$ & 9 & 29 & 2 & 47 & 13 \\
\hline Black Caribbean & 63 & $3 \cdot 2$ & 11 & 25 & 9 & 45 & 9 \\
\hline Black mixed-race & 68 & $3 \cdot 0$ & 7 & 34 & 16 & 35 & 7 \\
\hline South Asian & 118 & $3 \cdot 2$ & 9 & 24 & 12 & 52 & 3 \\
\hline \multicolumn{8}{|l|}{ I was satisfied with the advice I received $\left(P^{*}=0.607\right) \dagger$} \\
\hline Black African & 106 & $1 \cdot 9$ & 37 & 46 & 10 & 7 & 0 \\
\hline Black Caribbean & 54 & $1 \cdot 9$ & 43 & 33 & 15 & 6 & 4 \\
\hline Black mixed-race & 68 & $2 \cdot 0$ & 28 & 61 & 8 & 3 & 1 \\
\hline South Asian & 120 & 1.9 & 22 & 60 & 10 & 7 & 0 \\
\hline \multicolumn{8}{|l|}{ I felt confident about when to wean my baby $\left(P^{*}<0.001\right) \dagger$} \\
\hline Black African & 106 & $1 \cdot 6^{\mathrm{a}}$ & 51 & 42 & 5 & 3 & 0 \\
\hline Black Caribbean & 54 & $1 \cdot 6^{\mathrm{a}}$ & 54 & 35 & 6 & 6 & 0 \\
\hline Black mixed-race & 68 & $2 \cdot 2^{\mathrm{b}}$ & 25 & 46 & 16 & 13 & 0 \\
\hline South Asian & 120 & $1 \cdot 8^{\mathrm{a}}$ & 40 & 44 & 8 & 8 & 0 \\
\hline \multicolumn{8}{|l|}{ I was given clear advice about the current guidelines $\left(P^{*}<0.001\right) \dagger$} \\
\hline Black African & 105 & $2 \cdot 4^{\mathrm{c}}$ & 21 & 44 & 13 & 18 & 4 \\
\hline Black Caribbean & 54 & $2 \cdot 5^{\mathrm{c}}$ & 20 & 37 & 17 & 20 & 6 \\
\hline Black mixed-race & 68 & $2 \cdot 6^{\mathrm{c}}$ & 9 & 46 & 24 & 19 & 3 \\
\hline South Asian & 120 & $2 \cdot 0^{d}$ & 32 & 47 & 10 & 11 & 1 \\
\hline \multicolumn{8}{|l|}{ I felt anxious about when to wean my baby $\left(P^{*}<0.001\right)$} \\
\hline Black African & 102 & $3 \cdot 5^{\mathrm{e}}$ & 9 & 17 & 10 & 48 & 17 \\
\hline Black Caribbean & 54 & $3 \cdot 4^{\mathrm{e}}$ & 4 & 28 & 4 & 50 & 15 \\
\hline Black mixed-race & 68 & $2 \cdot 8^{\mathrm{f}}$ & 9 & 40 & 24 & 22 & 6 \\
\hline South Asian & 120 & $3 \cdot 3^{\mathrm{e}}$ & 3 & 28 & 14 & 52 & 4 \\
\hline \multicolumn{8}{|l|}{ I felt confused about when to wean my baby $\left(P^{\star}<0.001\right)$} \\
\hline Black African & 102 & $4 \cdot 0^{\mathrm{g}}$ & 0 & 14 & 4 & 54 & 28 \\
\hline Black Caribbean & 54 & $3 \cdot 8^{9}$ & 2 & 11 & 7 & 63 & 17 \\
\hline Black mixed-race & 68 & $3 \cdot 3^{\mathrm{h}}$ & 7 & 16 & 28 & 35 & 13 \\
\hline South Asian & 120 & $3 \cdot 5^{\mathrm{h}}$ & 4 & 13 & 16 & 63 & 5 \\
\hline \multicolumn{8}{|l|}{ I did not receive enough advice $\left(P^{\star}=0.691\right)$} \\
\hline Black African & 100 & $3 \cdot 5$ & 2 & 16 & 20 & 51 & 11 \\
\hline Black Caribbean & 54 & $3 \cdot 4$ & 7 & 15 & 22 & 44 & 11 \\
\hline Black mixed-race & 68 & $3 \cdot 4$ & 0 & 28 & 24 & 32 & 16 \\
\hline South Asian & 120 & $3 \cdot 4$ & 3 & 17 & 21 & 55 & 5 \\
\hline \multicolumn{8}{|l|}{ I received too much advice $\left(P^{\star}=0.991\right)$} \\
\hline Black African & 102 & $3 \cdot 5$ & 7 & 16 & 21 & 39 & 18 \\
\hline Black Caribbean & 54 & $4 \cdot 4$ & 13 & 11 & 11 & 48 & 17 \\
\hline Black mixed-race & 67 & $3 \cdot 4$ & 3 & 16 & 24 & 51 & 6 \\
\hline South Asian & 120 & $3 \cdot 4$ & 6 & 14 & 18 & 57 & 5 \\
\hline \multicolumn{8}{|l|}{ Total attitudinal scoret $(P<0.001 \ddagger, P=0.049 \S)$} \\
\hline \multicolumn{8}{|l|}{ Black African } \\
\hline Mean & \multicolumn{2}{|c|}{$3 \cdot 5^{i}$} & & & & & \\
\hline SD & \multicolumn{2}{|c|}{$1 \cdot 3$} & & & & & \\
\hline Black Caribbean & & & & & & & \\
\hline Mean & & $\cdot 6^{i}$ & & & & & \\
\hline SD & & $1 \cdot 2$ & & & & & \\
\hline Black mixed-race & & & & & & & \\
\hline Mean & & $3 \cdot 4^{j}$ & & & & & \\
\hline SD & & $1 \cdot 1$ & & & & & \\
\hline Total Black & & & & & & & \\
\hline Mean & & $3 \cdot 5$ & & & & & \\
\hline SD & & $1 \cdot 2$ & & & & & \\
\hline South Asian & & & & & & & \\
\hline Mean & & $3 \cdot 6^{i}$ & & & & & \\
\hline SD & & $1 \cdot 0$ & & & & & \\
\hline
\end{tabular}

Mean score calculated using scores assigned to responses to each statement from 1 = 'strongly agree' to $5=$ 'strongly disagree'.

${ }^{a-j}$ Mean scores within the same question with unlike superscript letters were significantly different $(P=0.05)$. For total attitudinal score, the mean score without the superscript was not included in the test.

${ }^{*}$ ANOVA analysis of means used to assess differences between scores for each ethnic group.

†For calculation of total attitudinal score, scoring is reversed on the positive questions; therefore higher total score indicates overall positivity.

$\ddagger P$ value for comparison across the three Black ethnic groups and South Asians.

$\S P$ value for comparison between total Blacks and South Asians. 
The South Asian mothers most commonly received advice in line with the DH guidelines; the most common advice from friends and family was to wean at or around 6 months (46\%) and similarly from health visitors (85\%).

\section{Factors associated with the decision to begin weaning} in the South Asian community

Like the other ethnicities, South Asian respondents reported being strongly influenced by the baby showing signs of readiness (63\% said this factor had 'a lot of influence'); however they were less influenced by the baby waking at night than the Black ethnicities $(P=0 \cdot 041)$.

\section{Feelings about weaning in the South Asian community} The South Asian respondents had a more positive attitude to the weaning experience $(P=0 \cdot 049)$ than the Black respondents. They reported strong agreement with the statements that they were given clear advice about the guidelines (79\%) and 55\% disagreed with the statement that they received conflicting advice. Eighty-four per cent agreed with the statement they were confident about when to wean, 56\% disagreed with the statement that they were anxious and $68 \%$ disagreed with the statement that they felt confused about when to wean (Table 4).

\section{Factors associated with weaning timing in the South Asian community}

In this population having accurate understanding of the $\mathrm{DH}$ weaning guidelines was independently associated with weaning timing, after adjusting for demographic factors and source of weaning advice $(F(1,189)=26 \cdot 4, P<0 \cdot 001)$ and resulted in later weaning, while being influenced by the baby waking in the night was independently associated with earlier weaning $(F(2,324)=18 \cdot 15, P<0 \cdot 001)$. No association was found with demographic factors, including being in receipt of benefits or educational attainment.

\section{Discussion}

Our study is the first to explore awareness of the weaning guidelines in BME populations and does so in a sample of parents living in London; we have assessed the influence of this and other important influences on weaning behaviour in a large group of Black African, Caribbean and South Asian parents and are able to draw some conclusions pertinent to individual key BME populations. Our findings show that an accurate knowledge of the weaning guidelines, in each of these communities, is important in influencing later weaning. However, overall understanding of the guidelines was considerably lower in these BME groups, with only $56 \%$ of respondents having an accurate knowledge and younger mothers particularly having a lower level of awareness than has been shown in our previous survey of a predominantly white population, in which $86 \%$ of respondents had an accurate understanding ${ }^{(7)}$.
We report here a poorer knowledge of the weaning guidelines and an earlier weaning age in Black ethnic groups compared with South Asians. In agreement with previous studies ${ }^{(6,11)}$, we found that early weaning remains an important issue in BME groups with $36 \%$ of Black Africans and $31 \%$ of Black Caribbeans in our survey weaning before 4 months (17 weeks), despite the relatively high level of educational attainment and the fact that these data were collected 8 years after the guideline change. This is important given the prevalence of chronic diseases in this population, such as diabetes and obesity, which may be associated with early weaning ${ }^{(2)}$. The Black ethnic groups reported that informal sources of advice were most influential in deciding when to wean, particularly the advice of the previous generation, and these sources of advice were associated with an earlier weaning age. We found a poorer attendance at antenatal classes among first-time mothers in the Black ethnicities than in the South Asian respondents; however, in all our ethnic groups, attendance was lower than reported for Caucasian first-time mothers, which may be an indication of a lack of engagement with formal advice surrounding pregnancy and infant care ${ }^{(7,15)}$. Furthermore, we have recognised distinct and important differences between parents of Caribbean and direct African ancestry. The Black Caribbean parents in our study were less likely to have attended antenatal education and significantly more likely to report health visitor advice as of 'no influence' in their weaning behaviour compared with parents of Black African ethnicity, suggesting a distinct lack of engagement with, or access to, formal health care in this community and demonstrating the need to consider these ethnic groups individually.

Health visitors are the primary source of infant feeding education in the UK and to ensure care is delivered to the most vulnerable ${ }^{(10)}$ the need for culturally sensitive infant feeding advice is acknowledged ${ }^{(18)}$. There has been very little work conducted to understand the barriers to engagement with $\mathrm{DH}$ feeding advice among the BME populations in the $\mathrm{UK}^{(13)}$. Work looking at BME engagement with healthcare services in general suggests that it is necessary to address literacy and language issues, improve relevance of communication materials by the inclusion of images of the represented cultures, improve general awareness of the services on offer and address culturally specific needs ${ }^{(19)}$. Part of the challenge of delivering culturally relevant infant feeding advice will be in making antenatal and postnatal education appealing and accessible in these communities, and cognisant of practical social factors which may prevent engagement. Our study also highlights specific differences between the weaning behaviours of key BME populations which are often considered under a collective umbrella and therefore a need to be more sensitive towards cultural groups within a diverse population.

Our South Asian parents reported a later weaning age and were less likely to wean early $(<17$ weeks) or very 
early ( $<8$ weeks). It was recognised that both informal and formal sources of advice were influential in this population; however, importantly there was a consistency between both these sources of advice and these were also in line with the weaning guidelines. Conversely the Black ethnicities, most particularly the Black mixed-race group, reported higher levels of anxiety, confusion and conflict in advice about weaning, which may be at least in part a reflection of the different advice they are receiving from family members and health professionals.

The dominance of informal family advice in influencing weaning in BME groups throws up a challenge for those promoting infant feeding best practice in the UK, particularly because the previous generation is likely to be perpetuating traditional cultural practices and beliefs that may be deemed inappropriate in light of the understanding we now have about the role weaning can play in health throughout the lifespan of the child. In our study the Black African parents reported a particular tendency to wean early to help the baby sleep through the night which $\mathrm{DH}$ weaning literature disregards as a sign of the readiness to accept solids. While we did not assess the importance of specific cultural beliefs and practices relating to weaning in our study, we acknowledge the importance of performing further qualitative work to better understand these influences.

The current study is unique in evaluating the level of awareness of the weaning guidelines in the population sampled and for being able to distinguish between important BME groups; in addition, we have collected attitudinal and behavioural data. However, the limitations of the study should be acknowledged. First, this is a self-selected sample of relatively well-educated mothers who were recruited from London alone - the sample will therefore have the associated biases of a self-selecting group and is unlikely to be nationally representative. We are also aware that among the South Asian community there will be further cultural differences between communities such as between Bangladeshi and Pakistani groups, which we were unable to explore because of our sample size. This was an interviewer-facilitated survey and we acknowledge the possibility of misunderstandings on both sides. We were unaware of any language barriers; however, it is possible that some of the questions may have been ambiguous to respondents with a poor command of English. We acknowledge that the survey is reporting historical behaviour and thus reverse causation is a possibility, in that the early introduction of solids may cause the incorrect reporting of the guidelines. We are aware of the general limitations associated with using Likert data as an indicator of attitudes, where possible additional statistical tests were carried out to confirm findings ${ }^{(20)}$. Finally, we acknowledge that we were using a previously piloted questionnaire that was not designed to collect some culturally specific information which would have added to our understanding of weaning in this population; for example, demographic information about country of birth, first weaning foods and whether cereals were added to bottled milk.

\section{Conclusions}

Lack of awareness of the DH weaning guidelines is common among these London BME parents, whose weaning behaviour is strongly influenced by informal advice. The study highlights that Black ethnicities may be a priority for improved infant feeding education, which also needs to address the beliefs of family members supporting mothers with infant feeding advice. Further qualitative research is necessary to elucidate the motivations and influences on weaning in these populations and to facilitate the development of infant feeding support which is accessible and salient for BME groups in the UK, to ensure that health visitors are supported in their delivery of the UK Healthy Child Programme to all ethnicities.

\section{Acknowledgements}

Sources of funding: This work was funded by King's College London as an academic project. A.P.M. received a small educational grant from Danone to support the writing of this paper. Danone had no role in the design, analysis or writing of this article. Conflicts of interest: No conflicts of interest are declared. Authors' contributions: L.M.G. conceived and designed the study, supervised the data collection and contributed to writing the manuscript. A.P.M. conceived and designed the study, conducted the statistical analyses, interpreted the data and wrote the manuscript. K.N. and G.H. contributed to data collection. P.M. provided statistical supervision. All authors contributed to critical revision of the manuscript for its intellectual content. Acknowledgements: The authors are grateful for the support of the London Sure Start Centres, the Tamil Welfare Centre and the other venues that allowed them to conduct interviews on their sites; and thank K. Patel and S. Kachwala who were involved in data collection. The authors would also like to acknowledge Danone for providing a small educational grant to support the writing of this paper.

\section{References}

1. British Dietetic Association Paediatric Specialist Group (2013) Complementary Feeding: Introduction of Solid Food to an Infant's Diet. BDA Policy Statement. Birmingham: British Dietetic Association; available at http://www.bda. uk.com/policies/WeaningPolicyStatement.pdf

2. European Food Safety Agency, Panel on Dietetic Products, Nutrition and Allergies (2009) Scientific Opinion on the appropriate age for introduction of complementary feeding of infants. EFSA Journal 7, 1423-1461.

3. Agostoni C, Decsi T, Fewtrell M et al. (2008) Complementary feeding: a commentary by the ESPGHAN Committee on Nutrition. J Pediatr Gastroenterol Nutr 46, 99-110. 
4. Northstone K, Emmett P \& Nethersole F (2001) The effect of age of introduction to lumpy solids on foods eaten and reported feeding difficulties at 6 and 15 months. J Hum Nutr Diet 14, 43-54.

5. Department of Health (2003) Infant Feeding Recommendation. http://webarchive.nationalarchives.gov.uk/+/www.dh. gov.uk/en/publicationsandstatistics/publications/publications policyandguidance/dh_4097197 (accessed September 2013).

6. Scientific Advisory Committee on Nutritions (2008) Infant Feeding Survey 2005: A commentary on infant feeding practices in the UK. Position statement by the Scientific Advisory Committee on Nutrition. http://www.sacn.gov.uk/ pdfs/sacn_ifs_paper_2008.pdf (accessed September 2013).

7. Moore AP, Milligan P \& Goff LM (2012) An online survey of knowledge of the weaning guidelines, advice from health visitors and other factors that influence weaning timing in UK mothers. Matern Child Nutr (Epublication ahead of print version).

8. King's Fund (2006) Access to Health Care and Minority Ethnic Groups. London: King's Fund; available at http:// www.kingsfund.org.uk/sites/files/kf/field/field_publication file/access-to-health-care-minority-ethnic-groups-briefingkings-fund-february-2006.pdf

9. White JM (2009) Weaning: what influences the timing? Community Pract 82, 34-37.

10. Department of Health (2009) Healthy Lives, Brighter Futures: The Strategy for Children and Young People's Health. London: Department of Health and Department for Children, Schools \& Families; available at http://webarchive.nationalarchives. gov.uk/+/www.dh.gov.uk/en/publicationsandstatistics/ publications/publicationspolicyandguidance/DH_094400

11. McAndrew F, Thompson J, Fellows L et al. (2010) Infant Feeding Survey 2010. Leeds/London/Dundee: Health and Social Care Information Centre, IFF Research and University of Dundee; available at http://www.esds. ac.uk/doc/7281/mrdoc/pdf/7281_ifs-uk-2010_report.pdf

12. Harris R (2004) Nutrition in the 21st century: what is going wrong? Arch Dis Child 89, 154-158.

13. Department of Health (2010) Breastfeeding and Introducing Solid Food: Consumer Insight Summary. London: Department of Health; available at https://www.gov.uk/ government/publications/breastfeeding-and-introducing-solidfoods-consumer-insight-summary

14. Kannan S, Carruth BR \& Skinner J (1999) Cultural influences on infant feeding beliefs of mothers. J Am Diet Assoc 99, 88-90.

15. Moore AP, Milligan P, Rivas C et al. (2012) Sources of weaning advice, comparisons between formal and informal advice, and associations with weaning timing in a survey of UK first-time mothers. Public Health Nutr 15, 1661-1669.

16. Boone HN Jr \& Boone DA (2012) Analysing likert data. J Extension 50, issue 2; available at http://www.joe.org/ joe/2012april/tt2.php

17. Johns R (2010). Likert items and scales. Survey Question Bank: Methods Fact Sheet 1 (March 2010). http://survey net.ac.uk/sqb/datacollection/likertfactsheet.pdf

18. Department of Health (2012) Preparation for Birth and Beyond: A resource pack for leaders of community groups and activities. https://www.gov.uk/government/uploads/ system/uploads/attachment_data/file/215386/dh_134728.pdf (accessed September 2013).

19. Szczepura A (2005) Access to health care for ethnic minority populations. Postgrad Med J 81, 141-147.

20. Carifio JC \& Perla RJ (2007) Ten common misunderstandings, misconceptions, persistent myths and urban legends about Likert scales and Likert response formats and their antidotes. J Soc Sci 3, 106-116. 